\title{
Vaginal Progesterone in Asymptomatic Women with Short Cervical Length on Ultrasound: is it Beneficial?
}

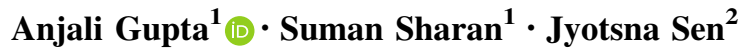

Received: 22 July 2015/Accepted: 28 August 2015/Published online: 18 September 2015

(C) Society of Fetal Medicine 2015

\begin{abstract}
The aim of the present study was to determine the efficacy of vaginal progesterone in asymptomatic women with a sonographic short cervix $(\leq 25 \mathrm{~mm})$ at $18-24$ weeks of gestation in reducing the risk of preterm birth. It was a prospective observational study carried out on 60 pregnant women attending the antenatal clinic in tertiary health institute between 18 and 24 weeks of gestation with ultrasonographically-measured short cervix. The women with cervical length $\leq 25 \mathrm{~mm}$ were alternately divided into two groups of 30 each. Group I was given $200 \mathrm{mg}$ vaginal micronized progesterone capsules and Group II was managed expectantly. Primary outcome was measured as spontaneous birth before 34 weeks of gestation. Secondary outcome was birth at $<32$ weeks, $<37$ weeks and the neonatal outcome. The demographic profile of women in both the groups was similar. The rate of spontaneous delivery before 34 and 37 weeks of gestation was significantly less in the progesterone group ( 3 vs $20 \% ; \mathrm{p}=0.044,6.6$ vs $26.7 \% ; \mathrm{p}=0.038$ ). There was no difference in birth weight $<2500 \mathrm{~g}$ and Apgar score $<7$ at $5 \mathrm{~min}$ in neonates of both the groups. Progesterone was associated with a significant reduction in composite neonatal morbidity ( 6.7 vs $33.3 \% ; \mathrm{p}=0.020$ ). There were no serious adverse events associated with the use of progesterone. Thus, in a woman with short cervical length, vaginal progesterone significantly lowers the preterm birth rate and composite neonatal morbidity.
\end{abstract}

Anjali Gupta

ajiii2003@yahoo.co.in

1 Department of Obstetrics \& Gynecology, Pt. B.D. Sharma, PGIMS, Rohtak 124001, Haryana, India

2 Department of Radiology, Pt. B.D. Sharma, Post Graduate Institute of Medical Sciences, Rohtak, India
Keywords Progesterone - Preterm labor - Short cervix · Micronized progesterone

\section{Introduction}

Preterm birth contributes significantly to perinatal morbidity and mortality. Most of the morbidity and mortality is experienced by babies born before 34 weeks [1]. Preterm birth rates have been reported to range from 5 to $7 \%$ of live births in some developed countries, but are estimated to be substantially higher in developing countries, about $8-15 \%$ [2]. Preterm neonates are at increased risk of developing respiratory distress syndrome, bronchopulmonary dysplasia, intraventricular hemorrhage, sepsis, nonclosure of ductus arteriosus, necrotizing enterocolitis, and disorders related to gestational age at birth [3].

The spontaneous preterm birth is a syndrome rather than diagnosis, caused due to varying etiologies. Cervical shortening is one of the risk factor for preterm birth [4]. However, many women who deliver preterm do not have any known risk factors [5] Biomarkers are used for predicting preterm birth [6]. However, it is not possible to obtain biomarkers in most of the clinics; therefore, the evaluation of the cervix with ultrasonography is important.

Cervical length is normally distributed and remains relatively constant in pregnancy until third trimester [7]. A cervical length of $25-50 \mathrm{~mm}$ is normal at 14-24 weeks in all pregnant women [8]. In most women who will have a preterm birth, a short cervical length is first noted at approximately 18-22 weeks of gestation; therefore, initial screening should be started at this time. A short cervical length by transvaginal ultrasound is a good screening predictor as it heralds onset of preterm delivery [9]. 
Preterm birth, in the absence of complicating factors, usually has a subclinical phase, with a gradually-effacing cervix, and offers a window of opportunity to the treating physician to intervene and improve outcomes.

Progesterone is considered a key hormone for pregnancy maintenance, and decline of progesterone action is implicated in the onset of parturition. If such a decline occurs in the mid-trimester, cervical shortening may occur and this would predispose to preterm delivery [10]. Several studies had shown higher endometrial progesterone concentrations in women who received vaginal progesterone despite lower serum concentrations, indicating some mechanism of direct transport between the vagina and uterus $[11,12]$.

The present study was conducted to determine the efficacy of vaginal progesterone in asymptomatic women with a sonographic short cervix $(\leq 25 \mathrm{~mm})$ at $18-24$ weeks of gestation in reducing the risk of preterm birth.

\section{Materials and Methods}

The present study was a prospective observational study carried out on 60 pregnant women attending the antenatal clinic in the Department of Obstetrics and Gynaecology, Pt. B.D. Sharma, PGIMS Rohtak between 18 and 24 weeks of gestation. The study has been approved by the institutional board of studies. Women with multiple gestation, having uterine contractions or premature rupture of membranes, uterine malformations, congenitally-malformed babies, first-trimester bleeding, placenta previa, gestational diabetes, hypertension, severe anemia, other medical illnesses like seizures, history of cerclage in previous pregnancy, and ultrasound findings suggestive of cervical incompetence, history of adverse reaction to progesterone, progesterone treatment within four weeks before enrollment were excluded. An informed written consent was taken from all the women. The women were subjected to detailed history and clinical examination. Routine antenatal investigations like hemoglobin, urine complete examination, blood grouping, glucose challenge test, thyroid-stimulating hormone (TSH) test, Australia antigen, human immunodeficiency virus (HIV) test, and venereal disease research laboratory (VDRL) test were carried out. Transabdominal scan (TAS) was done in all subjects with 3.5 $\mathrm{MHz}$ probe and those with cervical length $<3 \mathrm{~mm}$ were subjected to transvaginal scan (TVS). The ultrasonologist was provided with written material depicting how to measure the cervical length. Women were advised to drink two glasses of water, $1 \mathrm{~h}$ before TAS after voiding. If the cervix was not visualized, they were again called after $1 \mathrm{~h}$. The probe was kept in the anterior fornix and sagittal view of the cervix was obtained with echogenic endocervical mucosa all along the length of cervix. The distance between external and internal os was measured (Fig. 1). Cervical-length measurement was performed three times and shortest of these was chosen.

The women with cervical length $\leq 25 \mathrm{~mm}$ were alternately divided into two groups of 30 each. Group I was given $200 \mathrm{mg}$ vaginal micronized progesterone capsules daily at bed time until 37 weeks, rupture of membranes or delivery, whichever occurred first. Group II was managed expectantly. Women with history of prior preterm birth were included in Group I. No such woman was included in Group II as it would have been unethical if we manage these women expectantly.

Each woman was instructed to avoid intercourse and to restrict physical activity. The women were informed that side effects related to the administration of progesterone could include sleepiness, fatigue, headaches, and vaginal irritation. Follow-up visits were carried out every two weeks. The telephone numbers of the subjects were recorded so as to ensure the compliance. At each follow-up visit, the women were asked if they had noted any adverse effect of progesterone. Women who developed preterm labor in both groups were admitted to the hospital and were given intravenous fluids, tocolytic therapy, steroid administration, if clinically indicated. Administration of the study drug was continued during treatment for preterm labor, until delivery (in the absence of preterm rupture of membranes). All the subjects were followed up till delivery. Primary outcome was measured as spontaneous birth before 34 weeks of gestation. Secondary outcome was birth at $<32$ weeks, $<37$ weeks and the neonatal outcome. The data were compiled and analyzed using Chi square test and unpaired $t$ test. A p value $<0.05$ was considered significant.

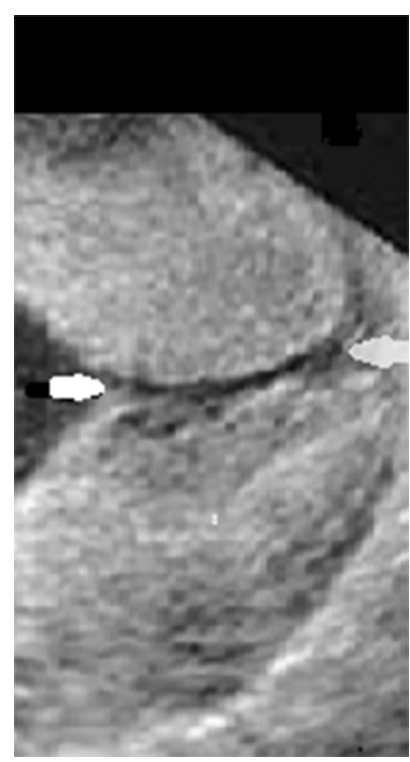

Fig. 1 TVS showing short cervical length 


\section{Results}

The number of women screened was 9648. Seventy-one women had cervical length $<3 \mathrm{~mm}$ on TAS and were subjected to TVS to get 60 women with short cervical length. There was no significant difference in baseline characteristics between the two groups (Table 1). In the present study, both the groups had women between 19-31 years age group. Maximum distribution was seen in the age group 20-24 years in both the groups followed by the age group 25-29 years. Most of the women in both the groups belonged to upper middle class. Majority of women enrolled for the study were primipara followed by nullipara. The difference in parity between two groups was statistically insignificant $(p=0.681)$. As the women with internal os dilatation were excluded from the study, so no woman required cervical encirclage. Five women had prior preterm delivery in Group I. Among both the groups, majority of women had normal body-mass index (BMI). The mean BMI of Group I was $23.80 \pm 2.2 \mathrm{~kg} / \mathrm{m}^{2}$ and that of Group II was $24.22 \pm 1.9 \mathrm{~kg} / \mathrm{m}^{2}$ and the difference was statistically found to be insignificant $(p=0.787)$. None among both the groups fell into underweight and obese BMI category. Majority of women in both the groups had cervical length measuring between 2.3 and $2.4 \mathrm{~cm}(73.3 \%$ each). In Group I, $16.7 \%$ and in Group II, $10 \%$ had cervical length between 2.1 and $2.2 \mathrm{~cm}$. Women were hospitalized only when they went into labor.

The gestational age at delivery is shown in Table 2 . The rate of spontaneous birth at $<34$ and $<37$ weeks was significantly lower in the progesterone group $(\mathrm{p}=0.44$, 0.038 , respectively). No women delivered before 28 weeks in both the groups. In both the groups, $80 \%$ of women delivered vaginally and $20 \%$ had cesarean delivery. No difference was present in both the groups regarding mode of delivery.
Mean birth weight did not differ in the two groups $(2.73 \pm 0.4 \quad$ vs $\quad 2.60 \pm 0.5, \quad \mathrm{p}=0.519 ; \quad \mathrm{RR}=1.15$; $\mathrm{CI}=0.22-5.9$ ). No neonate in both the groups had birth weight less than $1.5 \mathrm{~kg}$. Apgar score of $<7$ at $1 \mathrm{~min}$ was comparable in both the groups as shown in Table 3. It persisted at 5 min only in one neonate in Group II, while $100 \%$ of Group I and $96.7 \%$ of Group II neonates had Apgar score of $>7$ at $5 \mathrm{~min}(\mathrm{p}=0.313)$. The composite neonatal morbidity was significantly lower in progesterone group $(\mathrm{p}=0.02)$. However, there was no neonatal mortality in both the groups. There were no significant side effects of progesterone.

\section{Discussion}

Preterm birth is the most important cause of mortality and morbidity in newborns. Although the gestational age at which a fetus is viable is decreasing but the capacity to prevent preterm birth is limited. As the effectiveness of treatment of threatened preterm labor is limited, the research effort in this field is focusing on prevention. It has been shown that vaginal progesterone reduces the rate of preterm delivery at $<33$ weeks of gestation by $44 \%$, along with the rate of admission to the neonatal intensive care unit, respiratory distress syndrome, requirement for mechanical ventilation, and a composite score of neonatal morbidity/mortality [13].

According to Heath et al. [14] maternal age ( $<20$ years; $>35$ years), a low body mass index $(<19.8 \mathrm{~kg}$ / $\mathrm{m}^{2}$ ) and ethnicity (African-American or Afro-Caribbean) are associated with a shorter cervical length. Women who are either underweight or obese, with a BMI above 35, have a significantly higher risk of preterm birth as evident in the study by Schleubner [15]. The demographic profile was comparable in both the groups in our study and no
Table 1 Characteristics of the study groups

\begin{tabular}{llll}
\hline Characteristics & Group I $(\mathrm{n}=30)$ & Group II $(\mathrm{n}=30)$ & $\mathrm{p}$ value \\
\hline $\begin{array}{l}\text { Mean maternal age } \\
\text { Socioeconomic class }\end{array}$ & $23.9 \pm 2.8$ & $24.4 \pm 3.0$ & 0.366 \\
Upper & $5(16.7 \%)$ & $6(20 \%)$ & 0.945 \\
Upper middle & $23(76.6 \%)$ & $22(73.3 \%)$ & \\
Lower middle & $2(6.7 \%)$ & $2(6.7 \%)$ & 0.681 \\
Parity & & & \\
P0 & $12(40 \%)$ & $10(33.3 \%)$ & \\
P1 & $15(50 \%)$ & $17(56.7 \%)$ & 0.787 \\
P2 & $3(10 \%)$ & $2(6.7 \%)$ & \\
BMI & & $20(66.7 \%)$ & \\
$18.5-24.9$ (Normal) & $19(63.3 \%)$ & $10(33.3 \%)$ & \\
$25.0-29.9$ (Overweight) & $11(36.7 \%)$ &
\end{tabular}


Table 2 Gestational age (in weeks) at delivery

\begin{tabular}{llll}
\hline Period of gestation (weeks) & Group I $(\mathrm{n}=30)$ & Group II $(\mathrm{n}=30)$ & p value \\
\hline$<34$ & $1(3.3 \%)$ & $6(20 \%)$ & 0.044 \\
$<37$ & $2(6.6 \%)$ & $8(26.7 \%)$ & 0.038 \\
$<32$ & 0 & $1(3.3 \%)$ & 0.313 \\
\hline
\end{tabular}

Table 3 Neonatal outcome

\begin{tabular}{llcc}
\hline Neonatal parameters & Group I $(\mathrm{n}=30)$ & Group II $(\mathrm{n}=30)$ & p value \\
\hline Birth weight $<2500 \mathrm{~g}$ & $5(16.7)$ & $9(30)$ & \\
Apgar $<7$ at $1 \mathrm{~min}$ & $18(60)$ & $18(60)$ & 0.758 \\
Apgar $<7$ at $5 \mathrm{~min}$ & 0 & $1(3.3)$ & 0.313 \\
Admission to NICU & 0 & $3(10)$ & 0.076 \\
Phototherapy & $2(6.7)$ & $6(20)$ & 0.129 \\
RDS & 0 & $2(6.7)$ & 0.313 \\
Composite neonatal morbidity & $2(6.7)$ & $9(33.3)$ & 0.020 \\
\hline
\end{tabular}

$N I C U$ neonatal intensive-care unit, $R D S$ respiratory distress syndrome

demographic risk factor was present in either group which could have affected cervical length.

The utility of transvaginal cervical length measurement for assessing the risk of preterm birth has been well documented in a structured analysis of 14 trials that included a total of 2258 pregnant women. The accepted cutoff value for cervix length is $\leq 25$ before 24 weeks gestation (OR $2.76,95 \%$ CI 2.41-3.17) [16]. In our study the cervical length was measured between 18 and 24 weeks period of gestation in both the groups and the cutoff value taken was $\leq 25 \mathrm{~mm}$.

Initially, we have done the universal cervical length screening by TAS at the time of fetal anatomic survey and did TVS, if indicated, to reduce the burden on the ultrasonologist. This has also been proven to be cost effective [17].

In the present study, the rate of preterm birth at $<34$, $<32$, and $<37$ weeks is consistent with other studies [13, 18, 19]. Fonseca et al. [18] reported that patients allocated to receive vaginal progesterone had a lower rate of preterm delivery $(<34$ weeks) than those in the placebo group [19.2\% (24/125) vs $34.4 \%(43 / 125), p=0.02]$. They reported that $15.2 \%$ of preterm deliveries were prevented by progesterone, which is comparable to $16.7 \%$ in the present study. Hassan et al. [19] reported that the vaginal progesterone gel decreased preterm birth $<33$ weeks in comparison to placebo users (8.9 vs $16.1 \%$; $\mathrm{p}=0.02$ ). Romero et al. [13] found that treatment with vaginal progesterone was associated with a significant reduction in the rate of preterm birth $<33$ weeks $(12.4$ vs $22.0 \%$, RR 0.58 ; $95 \%$ CI 0.42-0.80), <37 weeks (RR 0.89; $95 \%$ CI 0.75-1.06). In a study, Franco et al. [20] reported that the rate of preterm birth at $<37$ weeks was 44.6 versus $51.7 \%$ for progesterone and placebo group $(p=0.36)$.
Our findings regarding birth weight are in agreement with the study of Hassan et al. [19] who reported no significant difference in birth weight less than $2.5 \mathrm{~kg}$ (25.6 vs $30.9 \%, \mathrm{p}=0.213)$. This implied that vaginal progesterone had no effect on birth weight and Apgar score. These findings are in accordance with the study of Romero et al. [13] who reported that there was no evidence of effect of vaginal progesterone on Apgar score $<7$ at 5 min and birth weight $<2500 \mathrm{~g}$.

Fonseca et al. [18] reported $24.3 \%$ neonatal intensivecare unit (NICU) admission in progesterone group and $30.4 \%$ in placebo group $(\mathrm{p}=0.30)$. Romero et al. [13] reported 20.7 versus $29.1 \%$ NICU admissions. The present study reported less number of NICU admissions as compared to these studies $[13,18]$ as less number of patients was enrolled in our study. The composite neonatal morbidity was significantly lower in progesterone group $(\mathrm{p}=0.020)$. This is in accordance with the study of Hassan et al. [19] (7.7 vs $13.5 \%, \mathrm{p}=0.04)$ and Romero et al. [13] (9.7 vs $17.3 \%$, RR $0.57 ; 95 \%$ CI $0.40-0.81$ ). Our study reported lower risk of respiratory distress syndrome in progesterone group which is similar to the study of Romero et al. [13] (6.1 vs $12.5 \%)$.

The strength of the study was that we measured the cervical length at the time of fetal anatomic survey. TAS was used first, followed by TVS. We did not study any cost effectiveness but reduced NICU admissions with progesterone, can be interpreted as cost-benefit effect. The index study has certain limitations as the study is not blinded; it is an open label study with small sample size and is not designed with sufficient power to comment separately on neonatal complications.

In the present study, treating the women having short cervical length with vaginal progesterone had significantly 
lowered preterm birth rate and composite neonatal morbidity. Although, progesterone had no direct effect on neonatal parameters, reduction in morbidity was attributed to reduction in rate of preterm birth. Women at high risk for spontaneous preterm birth can be identified by universal screening for short cervical length by TAS and TVS if required during routine fetal anatomic survey scan. Those with short cervical length should be offered prophylactic administration of vaginal progesterone to prevent preterm birth.

Funding None.

\section{Compliance with Ethical Standards}

Conflict of Interest None.

\section{References}

1. Royal College of Obstetricians and Gynaecologists (RCOG). Tocolysis for women in preterm labor. Green-top Guideline No. $1 \mathrm{~B} ; 2002$.

2. Lawn JE, Cousens SN, Darmstadt GL, et al. 1 year after the Lancet neonatal survival series-was the call for action heard? Lancet. 2006;367:1541-7.

3. Arisoy R, Yayla M. Transvaginal sonographic evaluation of the cervix in asymptomatic singleton pregnancy and management options in short cervix. J Pregnancy 2012;2012:201628:doi:10. 1155/2012/201628.epub.2012.

4. Norwitz ER, Caughey AB. Progesterone supplementation and prevention of preterm birth. Rev Obstet Gynecol. 2011;4(2):60-72.

5. Romero R, Yeo L, Miranda J, et al. A blueprint for the prevention of preterm birth: vaginal progesterone in women with a short cervix. J Perinat Med. 2013;41:27-44.

6. Mauldin JG, Newman RB. Preterm birth risk assessment. Semin Perinatol. 2001;25:215-22.

7. Cook CM, Ellwood DA. A longitudinal study of the cervix in pregnancy using transvaginal ultrasound. Br J Obstet Gynecol. 1996;103:16-8

8. Iams JD, Goldenberg RL, Meis PJ, et al. The length of the cervix and the risk of spontaneous premature delivery. N Engl J Med. 1996;334:567-72.
9. Khandelwal M. Vaginal progesterone in risk reduction of preterm birth in women with short cervix in the mid-trimester of pregnancy. Int J Women's Health. 2012;4:481-90.

10. Campbell S. Universal cervical-length screening and vaginal progesterone prevents early preterm births, reduces neonatal morbidity and is cost saving: doing nothing is no longer an option. Ultrasound Obstet Gynecol. 2011;38:1-9.

11. Cicinelli E, de Ziegler D, Bulletti C, et al. Direct transport of progesterone from vagina to uterus. Obstet Gynecol. 2000;95:403-6.

12. Miles RA, Paulson RJ, Lobo RA, et al. Pharmacokinetics and endometrial tissue levels of progesterone after administration by intramuscular and vaginal routes: a comparative study. Fertil Steril. 1994;62:485-90.

13. Romero R, Nicolaides K, Conde-Agudelo A, et al. Vaginal progesterone in women with an asymptomatic sonographic short cervix in the mid-trimester decreases preterm delivery and neonatal morbidity: a systematic review and metaanalysis of individual patient data. Am J Obstet Gynecol. 2012;206:124.e1-19.

14. Heath VC, Southall TR, Souka AP, et al. Cervical length at 23 weeks of gestation: relation to demographic characteristics and previous obstetric history. Ultrasound Obstet Gynecol. 1998;12:304-11.

15. Schleubner E. The prevention, diagnosis and treatment of premature labor. Dtsch Arztebl Int. 2013;110(13):227-36.

16. Crane JM, Hutchens D. Transvaginal sonographic measurement of cervical length to predict preterm birth in asymptomatic women at increased risk: a systematic review. Ultrasound Obstet Gynecol. 2008;31:579-87.

17. Maher MA, Abdelaziz A, Ellaithy M, et al. Prevention of preterm birth: a Randomised trial of vaginal compared with intramuscular progesterone. Acta Obstet Gynecol Scand. 2013;92:215-22.

18. Fonseca EB, Celik E, Parra M, et al. Progesterone and the risk of preterm birth among women with a short cervix. N Engl J Med. 2007;357:462-9.

19. Hassan SS, Romero R, Vidyadhari D, et al. Vaginal progesterone reduces the rate of preterm birth in women with a sonographic short cervix: a multicenter, randomized, double-blind, placebocontrolled trial. Ultrasound Obstet Gynecol. 2011;38:18-31.

20. DeFranco EA, O'Brien JM, Adair CD, et al. Vaginal progesterone is associated with a decrease in risk for early preterm birth and improved neonatal outcome in women with a short cervix: a secondary analysis from a randomized, double-blind, placebocontrolled trial. Ultrasound Obstet Gynecol. 2007;30:697-705. 